\title{
FUNÇÃO SOCIAL E RESPONSABILIDADE SOCIAL À LUZ DA CONSTITUIÇÃO FEDERAL DE 1988
}

\section{Social function and social responsibility to the constitution of the light of federal 1988}

\author{
HerthaUrquiza Baracho \\ Universidade Federal de Paraíba - UFPR -João Pessoa - Paraíba - Brasil \\ Augusto César Maurício de Oliveira Jatobá \\ Centro Universitário de João Pessoa - UNIPÊ - João Pessoa - Paraíba - Brasil
}

\begin{abstract}
Resumo: O presente artigo analisa os conceitos da função social e da responsabilidade social observados através de um prisma interdisciplinar, dentro de um contexto legal, doutrinário e jurisprudencial. O objetivo principal encontra-se na formulação de um conceito jurídico constitucional sobre a responsabilidade social empresarial. O estudo caminha para reconhecer a responsabilidade social como um valor jurídico implícito assegurado pelaConstituição Federal de 1988 natentativa de garantir a dignidade da pessoa humana e a justiça social, finalidades da atividade econômica. Cumpre informar, quanto à metodologia utilizada, que se trata de pesquisa bibliográfica e, como métodos de procedimento, serão usados o histórico e o descritivo.
\end{abstract}

Palavras-chave:Função Social;Responsabilidade Social;Constituição Federal.

Abstract: The present article analyzes the concepts of social function and the socialresponsibilityo article ponsibility observed through an interdisciplinary perspective, within a legal framework, doctrinal and jurisprudential. The objective is to formulate a legal concept constitutional on corporate social responsibility. The study walks to recognize the social responsibility as a legal value implicit ensured by Federal Constitution of 1988 in an attempt to ensure the dignity of the human person and social justice purposes of economic activity. Should be informed as to the methodology used, it is literature and as procedure methods will be used historical and descriptive.

Keywords:Social Function; Social Responsibility; Federal Constitution

Revista do Direitoda UNISC, Santa Cruz do Sul, v.1, n. 45 , p. 46- 60 , jan. - abri. 2015. 


\section{INTRODUÇÃO}

Ao longo dos anos, o Estado passou por grandes transformações estruturais e organizacionais, saindo da fase Liberal, passando pelo Estado Social e adentrando a atual concepção Neoliberal. Com essa nova ideologia, o Estado passa a intervir cada vez menos no âmbito social. Como consequência desse afastamento, emerge o Terceiro Setor que, trabalhando paralelamente com o Estado, busca efetivar políticas públicas voltadas para o social.

A sociedade civil organizada assume então um papel de destaque na conjuntura jurídica, pois auxilia o Estado na consecução dos seus fins. No plano nacional, essa relação se tona mais efetiva a partir do século $X X$, momento em que se percebeu que com a descentralização de poder as prestações estatais se tornariam mais eficientes.

É sob esse panorama que se encontra a necessidade de todos os setores se amoldarem a esse novo paradigma, como é o caso das sociedades empresariais. Nessa conjuntura a Empresa é convocada a cumprir sua função social, sem deixar de lado a sua tarefa primeira que é o lucro, devendo contribuir para o desenvolvimento nacional sustentável.

Hodiernamente, as obrigações para com o social incorporam-se na política das empresas, surgindo a noção de empresa socialmente responsável. Emerge a Responsabilidade Social que encontra respaldo no conceito jurídico de desenvolvimento sustentável, uma vez que também é de responsabilidade das empresas o desenvolvimento econômico, social e a preservação ambiental.

Finalmente, em face de, na doutrina, carência de definições jurídicas a respeito da responsabilidade social, o objetivo deste trabalho é contribuir para haver preenchimento dessa lacuna, buscando fragmentar juridicamente a noção que se tem atualmente sobre esse instituto para, posteriormente, unificar e formar um conceito à luz da Constituição Federal.

\subsection{QUE É FUNÇÃO SOCIAL?}

Revista do Direitoda UNISC, Santa Cruz do Sul, v.1, n. 45, p. 46- 60, jan. - abri. 2015. 
Para iniciar esse estudo é necessário começar destacando que, conforme UadiLammêgoBulos (2014), a noção de Função Social ainda é tida como vaga e imprecisa em meio à doutrina. Assim, para uma melhor compreensão desse instituto, faz-se necessário identificar sua origem e buscar entender seus significados para,ao final do presente tópico, formular uma concepção basilar e então responder à pergunta ora proposta.

Segundo José Diniz de Moraes (1999), a palavra função provém do Latim functioe seria traduzida como execução, exercício, e também como direito ou dever de agir. Ainda segundo o dicionário Aurélio de língua portuguesa, função significa exercício de atribuições, uso especial para que algo é concebido.

De acordo com Eduardo Tomasevinicius Filho (2005), a noção de função social foi idealizada de forma pioneira por Santo Tomás de Aquino. Este afirmava que os bens tidos como individuais possuíam um destino comum, finalidade que deveria ser respeitada por todos.

Juridicamente, essa ideia de função social só apareceu com a promulgação da Constituição Mexicana de 1917, no contexto do pós-guerra, quando eclode a disseminação dos direitos sociais e a limitação do poder do Estado. Foi a partir do advento desse diploma legal que conhecemos a expressão "para o interesse do povo", caracterizando a primeira noção jurídica de função social.

Seguindo essa tendência, surge a constituição alemã de 1919, que de maneira mais técnica, contemplava em seu texto, no artigo 153, um comando direcionado a função social da propriedade. Esse mandamento foi repetido na atual Constituição da Alemanha datada de 1949, que assim o expõe:

Artigo 14 [Propriedade - Direito de sucessão - Expropriação] (1) A propriedade e o direito de sucessão são garantidos. Seus conteúdos e limites são definidos por lei. (2) A propriedade obriga. Seu uso deve servir, ao mesmo tempo, ao bem comum.

Partindo dessas noções básicas, mas trazendo agora o termo para ser analisado sob o prisma do Direito, função seria a razão de existir determinado instituto, ou seja, o motivo pelo qual ele é criado. Seguindo a mesma linha de pensamento, o professor Augusto Geraldo Teizen Júnior (2009)revela que "usa-se do termo função, na análise institucional do direito, para designar a

Revista do Direitoda UNISC, Santa Cruz do Sul, v.1, n. 45, p. 46- 60, jan. - abri. 2015. 
finalidade legal de um instituto jurídico, ou seja, o bem ou valor em razão do qual existe, segundo a lei, esse conjunto estruturado de normas".

Mas esse não é o único significado do termo função dentro da Ciência Jurídica. Como é notório, todas as pessoas, sejam elas leigas ou especializadas, sabem que o Direito tem uma linguagem própria, e sendo assim, existem definições mais específicas sobre determinados termos, sob pena de esvair-se os significados dos institutos jurídicos.

A melhor definição que se amolda a esse estudo é aquela trazida por Eros Roberto Grau (1981) que ensina ser a função um poder. Esse poder não seria ilimitado, ou seja, o seu titular não poderia exercê-lo apenas visando a seu interesse, deveria também respeitar os direitos de terceiros, da coletividade. É a partir dessa noção que se detectao surgimento da conotação Função Social dentro da doutrina jurídica brasileira.

Nesse mesmo trilhar, o professor Fábio Konder Comparato (1986, p. 75) diz que função seria um poder, mas limitado pelo adjetivo "social" que estaria ligado ao cumprimento de determinado objetivo, o qual corresponderia aos interesses coletivos. Afirma o autor:

\begin{abstract}
Mas a noção de função, no sentido que é empregado o termo nesta matéria, significa um poder, mais especificamente, o poder de dar ao objeto da propriedade destino determinado, de vinculá-lo a certo objetivo. O adjetivo social mostra que esse objetivo corresponde ao interesse coletivo e não ao próprio dominus; o que não significa que não possa haver harmonização entre um e outro. Mas, de qualquer modo, se se está diante de um interesse coletivo, essa função social da propriedade corresponde a um poder-dever do proprietário, sancionável pela ordem jurídica.
\end{abstract}

Mas o que seria o interesse coletivo? Pode-se dizer que o interesse público seria a soma dos interesses individuais, mas com uma finalidade coletiva, ou seja, voltado à promoção da existência digna de todos e da realização da justiça social. Sobre o tema, o professor Celso Antônio Bandeira de Mello (2010, p.61) faz a seguinte colocação:

[...] o interesse público deve ser conceituado como interesse resultante do conjunto de interesses que os indivíduos pessoalmente têm quando considerados em sua qualidade de membros da sociedade e pelo simples fato de o serem.

Mas então, o que seria função social? Inicialmente precisa-se ter em mente que a função social não é uma forma de limitação da propriedade. $\mathrm{Na}$ verdade, busca-se conceituar a função social como um poder-dever atrelado ao

Revista do Direitoda UNISC, Santa Cruz do Sul, v.1, n. 45, p. 46- 60, jan. - abri. 2015. 
cumprimento decerta finalidade, qual seja, a satisfação de determinada necessidade social, necessidade essa que irá variar de acordo como o tempo e o espaço.

Segundo Ronaldo Poletti (1999), no Brasil, a contemplação jurídica do princípio da função social se deu com o advento da Constituição de 1934. Hodiernamente, a função social tem expressa previsão constitucional. É o que podemos extrair ao verificar oart. 5ํ, XXIII e o art. 170, III da Constituição Federal que assim dispõe:

Art. 5 Todos são iguais perante a lei, sem distinção de qualquer natureza, garantindo-se aos brasileiros e aos estrangeiros residentes no País a inviolabilidade do direito à vida, à liberdade, à igualdade, à segurança e à propriedade, nos termos seguintes:

XXIII - a propriedade atenderá a sua função social;

Art. 170. A ordem econômica, fundada na valorização do trabalho humano e na livre iniciativa, tem por fim assegurar a todos existência digna, conforme os ditames da justiça social, observados os seguintes princípios:

III - função social da propriedade;

A positivação da função social trazida pela Constituição Federal de 1988 evidencia a preocupação do legislador em imprimir uma conotação social ao Estado brasileiro, fazendo com que esse princípio fosse de alcanceamplo e eficaz. Para entender melhor essa temática, passa-se para o tópico seguinte.

\section{A FUNÇÃO SOCIAL NO CONTEXTO DA CONSTITUIÇÃO}

A partir de uma análise dos artigos $1^{\circ}$ ao $4^{\circ}$ da atual Constituição Federal, percebe-se que a denominada Constituição Cidadã aponta para valores sociais que o Brasil está obrigado a perquirir.

O alcance da função social no contexto da Constituição Federal de 1988 é de tamanha grandeza que o professor Gustavo Tepedino (2005, p. 103), ensina que:

Nunca porém, em toda história constitucional brasileira, a funçãosocial recebeu tratamento tão amplo e tão concretizante como o quese vê na atual Constituição. Não foi ela apenas referida como direitoe garantia individual e como princípio da ordem econômica, masganhou, ao lado de seu adequado posicionamento no sistemaconstitucional, indicação de um conteúdo mínimo, expresso no quetange à propriedade imobiliária.

É preciso realçar que a função social decorre do princípio da socialidade e se apresenta sobre três primas comumente usados na Ciência Jurídica, que

Revista do Direitoda UNISC, Santa Cruz do Sul, v.1, n. 45, p. 46- 60, jan. - abri. 2015. 
são: a função social do contrato, a função social da propriedade e a função social da empresa.

A respeito da função social do contrato, que encontra previsão no artigo 421 do nosso Código Civil, é importante destacar que ela é concretizada quando respeitadas as normas legais, objetivando-se a livre circulação de riquezas, desde que sejam respeitadas a dignidade da pessoa humana e a solidariedade. Sobre o tema, colaciona-se o pensamento do professor Humberto Theodoro Júnior (2008, p. 53) que consegue, nessa passagem, fechar o conceito desse instituto, ao afirmar:

\begin{abstract}
A função social do contrato corresponde à necessidade sentida pelo Estado moderno de limitar a autonomia contratual, em face da exigência social de "garantireinteressigenerali o colettivi" que não se satisfaziam dentro da sistemática do estado Liberal. A liberdade de contratar, nessa ordem de ideias, não pode contrastar com a utilidade social em temas como segurança, liberdade, dignidade humana, devendo sobrepor à autonomia contratual interesses coletivos como os ligados à educação, à saúde, os transportes, a utilização adequada das fontes de energia, à tutela do meio ambiente, a proteção a certos setores produtivos, etc. Há uma reciprocidade, nesse aspecto, entre as regras de limitação da propriedade e as que restringem a autonomia contratual. Incluem-se, ainda, no âmbito das limitações da liberdade de contratar (função social) a tutela da livre concorrência no mercado (combate aos trusts e às praxes de dominação de mercado) e à tutela das partes débeis das relações de mercado (os consumidores, no que diz respeito à propaganda enganosa, aos contratos standard, à contratação à distância, etc).
\end{abstract}

Em relação à função social da propriedade destaque-sea importância da Igreja como difusora desse pensamento. Como anteriormente mencionando, um dos grandes defensores da ideia de que a propriedade havia de ter um caráter social, ou seja, de que o homem não deveria dar um destino individual aos bens exteriores, mas uma finalidade comum, foi Santo Tomás de Aquino.

Assim, durante a idade média, a igreja pregava que a propriedade deveria atender tanto aos anseios individuais como aos coletivos, aceitando a possibilidade de existir um bem público que não pudesse ser objeto de posse individual, sob o risco de afrontar o bem comum.

Esse pensamento, como vimos anteriormente, acabou por influenciar as Constituições Mexicana (1917) e Alemã (1919). No âmbito interno, a Constituição brasileira de 1988 adota como cláusula pétrea, no art. 5ํㅗ XXIII, o seguinte mandamento:

Revista do Direitoda UNISC, Santa Cruz do Sul, v.1, n. 45, p. 46- 60, jan. - abri. 2015. 
Art. 5 Todos são iguais perante a lei, sem distinção de qualquer natureza, garantindo-se aos brasileiros e aos estrangeiros residentes no País a inviolabilidade do direito à vida, à liberdade, à igualdade, à segurança e à propriedade, nos termos seguintes:

XXIII - a propriedade atenderá a sua função social;

Sobre o tema, o professor José Afonso da Silva (1999, p. 286) diz que "a função social se manifesta na própria configuração estrutural do direito de propriedade, pondo-se concretamente como elemento qualificante na predeterminação dos modos de aquisição, gozo e utilização dos bens". Assim, concorda-se com o pensamento do autor para afirmar que a função social está intrinsecamente ligada ao instituto da propriedade, não podendo ser desvinculada desta, sob pena de desaparecer o direito de propriedade juridicamente protegido.

Definida as duas primeiras vertentes que se extraem da função social, passa-se agora a analisar a função social da empresa. Nessa parte do estudo, a intenção é de apresentar noções desse instituto enquanto atividade exercida pelo empresário.

Sabe-se que a empresa não tem por finalidade única e exclusivamente a geração de lucros para seus sócios. Ela é uma expressão social, econômica e financeira, que gera renda capaz de influenciar a comunidade na qual se encontra inserida. Isso porque o Estado Democrático de Direito abriu espaços para a livre iniciativa de participar de maneira direta na circulação e produção de bens e serviços, objetivando um maior desenvolvimento social.

Mas então, o que seria a função social da empresa? Pode-se dizer que é quando a empresa atende aos interesses da coletividade, ou seja, os bens e serviços que ela produz são compatíveis com os anseios da comunidade. Assim, uma empresa que gera emprego, renda e gera produtos úteis para a sociedade estaria cumprindo sua função social. Nesse sentido, colaciona-se o entendimento da Ministra Nancy Andrighi, no Agravo Regimental ㄲo 110.250 DF, que diz:

A função social da empresa exige sua preservação, mas não a todo custo. A sociedade empresária deve demonstrar ter meios de cumprir eficazmente tal função, gerando empregos, honrando seus compromissos e colaborando com o desenvolvimento da economia, tudo nos termos do art. 47 da Lei no 11.101/05.

Revista do Direitoda UNISC, Santa Cruz do Sul, v.1, n. 45 , p. 46- 60 , jan. - abri. 2015. 
É bom esclarecer que o objetivo primeiro da empresa continua sendo o lucro. A função social jamais poderia anular a renda da empresa. Sem o lucro a empresa deixa de existir e, dessa forma,jamais poderia conseguir cumprir a sua função social. A bem da verdade, a empresa não deve proporcionar benefícios apenas para os sócios e acionistas, mas sim para toda a comunidade. Partindo desse entendimento, percebe-se que a função social atinge diretamente os proprietários, pois limita seus direitos em torno da propriedade, devendo compatibilizar o seu interesse privado com o interesse social esperado pela comunidade.

Dessa forma, diante do que fora estudado nesse tópico, a empresa, sob a ótica da função social presente na constituição, não pode apenas visar o lucro, deverá contribuir para o desenvolvimento nacional (art. $3^{\circ}$, inc. II, CF/88) através do pagamento devido de tributos e contribuir, ao lado do Estado, na busca pelo pleno emprego (art. 170을 inc. VIII, CF/88), o que representa, ultima ratio, a tentativa de assegurar a dignidade da pessoa humana (art. 1ㅇ, inc. III, $\mathrm{CF} / 88)$ dispõe que:

Art. 1ำ A República Federativa do Brasil, formada pela união indissolúvel dos Estados e Municípios e do Distrito Federal, constituise em Estado Democrático de Direito e tem como fundamentos:

III - a dignidade da pessoa humana;

É aspirando a ajudar o Estado a conseguir cumprir este valor fundamental que se adentra no estudo da responsabilidade social da empresa.

\section{RESPONSABILIDADE SOCIAL DAS EMPRESAS}

OEstadoe a comunidade empresarial, que são duas instituições de grande importância no país, têm responsabilidade de resolver problemas de interesse público e agir em prol da sociedade,embora dependam sempre da aceitação por parte da comunidade à qual pertencem.

Importante enfatizar que os estudos no setor empresarial e acadêmico, sobre a importância da responsabilidade social corporativa, tiveram início nos Estados Unidos e, no final dos anos 60, na Europa (ASHLEY et al, 2005). Partindo dessa ideia, Barbieri e Cajazeira (2012) nos informam que desde a década de 70 muitas empresas voltaram suas atenções para significativas

Revista do Direitoda UNISC, Santa Cruz do Sul, v.1, n. 45, p. 46- 60, jan. - abri. 2015. 
áreas de preocupação social e continuam a fazê-lo. Ainda que sejam apenas abordagem a título de obrigação social com relação à responsabilidade social, são áreas importantes para todas as empresas.

No contexto nacional, nos anos de 1980 , foi lançado um modelo de balanço social pela Fundação Instituto de Desenvolvimento Empresarial Social (FIDES), que, ao seu final, não obteve um resultado satisfatório. Já na década de 90 , a temática começou a sensibilizar algumas empresas e recebeu forte aceitação por parte de entidades não-governamentais e institutos de pesquisa pelo engajamento da iniciativa privada nas novas políticas sociais do governo.

Assim, a história da responsabilidade social incorporada no mundo dos negócios é um pouco recente e as organizações têm um papel importante no que se refere a dar continuidade na construção dessa narração. É a sua própria história o alicerce para o seu conceito.

De fato, ainda são poucos os estudos que versam sobre a responsabilidade social com um enfoque jurídico, tendo sido comumente alvo de estudos nas áreas das ciências sociais, como por exemplo, em Administração, Sociologia, entre outras. Isso é explicável porque esse assunto sempre foi abordado pelo prisma da gestão empresarial, sempre deixando à margem qualquer preocupação que gerasse efeitos no mundo jurídico.

A responsabilidade social não pode ser vista comoobrigação social, ou seja, uma obrigação prevista em lei. Também não deve ser confundida como uma resposta para a sociedade. Boff (2011) enfatiza que a responsabilidade social deve ser vista como uma obrigação que as organizações assumem, através da busca por metas que, a médio e longo prazo, sejam boas para a empresa e para a comunidade na qual está envolvida.

\subsection{CONCEITO}

Usualmente, é comum encontrar várias interpretações para o conceito de responsabilidade social. Essa característica decorre do fato de que cada grupo empresarial traz consigo a ideia de que ela é um componente de sua missão enquanto sociedade empresária. Assim, esse conceito é modificado de acordo com as pretensões que as empresas têm em mente.

Como fora mencionando anteriormente, poucos estudos jurídicos

Revista do Direitoda UNISC, Santa Cruz do Sul, v.1, n. 45, p. 46- 60, jan. - abri. 2015. 
versam sobre a responsabilidade social, fato esse que encontra seu fundamento na ideia de que não existe no ordenamento jurídico brasileiro qualquer norma que defina a responsabilidade social. Mas,isso não poderá ser empecilho para o estudo desse instituto, pois "ainda que o conceito não seja definitivo e estático, responsabilidade social empresarial é uma construção histórica da sensibilização do mundo empresarial frente às necessidades das comunidades que estão em seu interior ou em seu entorno". (POLACCHINI, 2008, p. 60)

Diante dessa ótica, convém citar o conceito do Instituto ETHOS (2013, p. 16) sobre a temática:

Responsabilidade Social Empresarial é a forma de gestão que se define pela relação ética e transparente da empresa com todos os públicos com os quais ela se relaciona e pelo estabelecimento de metas empresariais compatíveis com o desenvolvimento sustentável da sociedade, preservando recursos ambientais e culturais para as gerações futuras, respeitando a diversidade e promovendo a redução das desigualdades sociais.

Partindo da conceituação trazida pelo Instituto Ethos, pretende-se construir uma concepção mais jurídica. Leva-se em consideração os conhecimentos relacionados às palavras "ética" e "transparência", detentoras de valores morais e de conceitos abertos.

Ainda de acordo com o mesmo Instituto, em parceria com a Controladoria Geral da União, ética "representa os valores do comportamento humano que atuam para o bem do indivíduo e da sociedade, como a moral, justiça, transparência, retidão, entre outros valores que mostram uma boa conduta social" (CONTROLADORIA GERAL DA UNIÃO e ETHOS, 2009, p.60).

Já o termo transparência pode ser analisado à luz da Constituição, pois incorpora em seu significado dois princípios constitucionais insculpidos no art. 37 da Constituição Federal:

Art. 37. A administração pública direta e indireta de qualquer dos Poderes da União, dos Estados, do Distrito Federal e dos Municípios obedecerá aos princípios de legalidade, impessoalidade, moralidade, publicidade e eficiência e, também, ao seguinte: (Redação dada pela Emenda Constitucional no 19, de 1998)

O primeiro é o princípio da probidade, que decorre do princípio da moralidade estatuído no artigo em comento. Exige-se que os administradores respeitem os bons costumes, a moral, o bom senso e a justiça. Importe v.1, n. 45, p. 46- 60, jan. - abri. 2015. 
destacar que a probidade encontra definição positivada no ordenamento jurídico, nesse sentido DI PIETRO (2002, p.305), diz que:

A Lei 8.666/93 faz referência à moralidade e à probidade, provavelmente porque a primeira, embora prevista na Constituição, ainda constitui um conceito vago, indeterminado, que abrange uma esfera de comportamentos ainda não absorvidos pelo Direito, enquanto a probidade ou, melhor dizendo, a improbidade administrativa já tem contornos bem mais definidos no direito positivo $[\ldots] "$.

segundo princípio, que decorre do conceito de transparência, é o da publicidade, também positivado no artigo 37 da Magna Carta, que significa tornar atos em geral do conhecimento do público, da sociedade. Nesse trilhar, a transparência está ligada ao acesso de informações do mundo empresarial que devem ser disponibilizadas para a comunidade.

A parte final do conceito de Responsabilidade Social trazida pelo Instituto Ethos - "[...] compatíveis com o desenvolvimento sustentável da sociedade, preservando recursos ambientais e culturais para as gerações futuras, respeitando a diversidade [...] - se assemelha ao mandamento constitucional contido no caputdo artigo 225 e em seu $\S 1^{\circ}$, que assevera:

Art. 225. Todos têm direito ao meio ambiente ecologicamente equilibrado, bem de uso comum do povo e essencial à sadia qualidade de vida, impondo-se ao Poder Público e à coletividade o dever de defendê-lo e preservá-lo para as presentes e futuras gerações.

$\S 1$ 10 - Para assegurar a efetividade desse direito, incumbe ao Poder Público:

I - preservar e restaurar os processos ecológicos essenciais e prover o manejo ecológico das espécies e ecossistemas;

II - preservar a diversidade e a integridade do patrimônio genético do País e fiscalizar as entidades dedicadas à pesquisa e manipulação de material genético;

III - definir, em todas as unidades da Federação, espaços territoriais e seus componentes a serem especialmente protegidos, sendo a alteração e a supressão permitidas somente através de lei, vedada qualquer utilização que comprometa a integridade dos atributos que justifiquem sua proteção;

IV - exigir, na forma da lei, para instalação de obra ou atividade potencialmente causadora de significativa degradação do meio ambiente, estudo prévio de impacto ambiental, a que se dará publicidade;

V - controlar a produção, a comercialização e o emprego de técnicas, métodos e substâncias que comportem risco para a vida, a qualidade de vida e o meio ambiente;

VI - promover a educação ambiental em todos os níveis de ensino e a conscientização pública para a preservação do meio ambiente;

VII - proteger a fauna e a flora, vedadas, na forma da lei, as práticas que coloquem em risco sua função ecológica, provoquem a extinção de espécies ou submetam os animais a crueldade.

Revista do Direitoda UNISC, Santa Cruz do Sul, v.1, n. 45, p. 46- 60, jan. - abri. 2015. 
Um ponto interessante que merece destaque é o conteúdo trazido pela Norma Brasileira ABNT NBR 16001: 2004 que estabelece o seguinte:

Esta norma estabelece os requisitos mínimos relativos a um sistema da gestão da responsabilidade social, permitindo à organização formular e implementar uma política e objetivos que levem em conta os requisitos legais e outros, seus compromissos éticos e sua preocupação com a:

promoção da cidadania; promoção do desenvolvimento sustentável; e transparência das suas atividades.

Eli da Veiga ( 2005, p. 171) elabora o conceito de desenvolvimento sustentável que será fundamental para a construção do conceito de responsabilidade social.

\begin{abstract}
A abordagem fundamentada na harmonização de objetivos sociais, ambientais e econômicos, primeiro chamada de ecodesenvolvimento, e depois de desenvolvimento sustentável, não se alterou substancialmente nos vinte anos que se separaram as conferências de Estocolmo e do Rio. E acredita que permanece válida, na recomendação de objetivos específicos para oito das suas dimensões: social, cultural, ecológica, ambiental, territorial, econômica, política nacional e política internacional. No que se refere às dimensões ecológicas e ambientais, os objetivos de sustentabilidade formam um verdadeiro tripé: 1) preservação do potencial da natureza para a produção de recursos renováveis; 2) limitação do uso de recursos não renováveis; 3) respeito e realce para a capacidade de autodepuração dos ecossistemas naturais
\end{abstract}

Nessa parte do estudo, depois de ter fragmentado juridicamente 0 conceito trazido pelo Instituto Ethos acerca do tema, procura-se unificar as partes para formar $o$ entendimento jurídico constitucional sobre a Responsabilidade Social.

Assim, diante do que fora pontuado, pode-se dizer que a Responsabilidade Socialé a performanceéticaesperadade uma comunidade ou deuma organização empresarial que, juntamente com 0 Estado, busca concretizar o desenvolvimento nacional sustentável, no âmbito econômico, social e ambiental, devendo observância a valores consagrados constitucionalmente com o objetivo de promover a dignidade da pessoa humana.

O conceito formulado faz perceber que a ideia de responsabilidade social passeia em todo o texto constitucional, como um valor implícito, devendo o intérprete usar da hermenêutica para a devida aplicação a cada caso concreto.

Revista do Direitoda UNISC, Santa Cruz do Sul, v.1, n. 45, p. 46- 60, jan. - abri. 2015. 


\section{CONSIDERAÇÕES FINAIS}

O artigo abordou a Função Social para, em momento posterior, investigar a Responsabilidade Social, ambos à luz da Constituição Federal de 1988. Como fora evidenciado, o segundo conceito ainda não se encontra positivado; tampouco, em meio à doutrina, encontram-se estudos significativos que busquem fomentar um conceito jurídico.

Enfim, procurou-se contribuir com um conceito jurídico que pudesse servir de norte para novas investigações acadêmicas e demostrar que a Responsabilidade Social é valor constitucional implícito, intrínseco à estrutura da Empresa, que se encontra inserida em um contexto social, dando efetividade às suas funções, sejam sociais, econômicas ou ambientais, revelando uma conotação mais humanista, visando, em última instância, à promoção da dignidade da pessoa humana.

\section{REFERÊNCIAS}

ASHLEY, P. A et al. Ética e responsabilidade social nos negócios. São Paulo: Saraiva, 2005.

BANDEIRA DE MELLO, Celso Antônio. Curso de Direito Administrativo. 27ํㅡㄹ. São Paulo: Malheiros, 2010.

BARBIERI, J. C.; CAJAZEIRA, J. E. Responsabilidade social empresarial e empresa sustentável: da teoria à prática. São Paulo: Saraiva, 2012.

BOFF, L. Uma lei de responsabilidade sócio-ambiental. Quem deve cuidar do Planeta. Rio de Janeiro, jan. 2011. Disponível em:<http://www.leonardoboff.com/site/lboff.htm>. Acesso em: 01 dez. 2014.

BRASIL. Constituição (1988). Constituição da República Federativa do Brasil: promulgada em 5 de outubro de 1988. Disponível em: <http://www.planalto.gov.br/ccivil_03/Constituicao/Constituicao.htm>. Acesso em: 07 dez. 2014.

BRASIL. Superior Tribunal de Justiça. Agravo Regimental no Conflito de Competência no 110.250 (2010/0016441-3). Recorrente: VIPLAN - Viação Planalto Ltda. Recorrido: Viação Aérea São Paulo S/A VASP e outros. Relator: Ministra Fátima Nancy Andrighi. Brasília, 08 set. 2010. Disponível em: <http://www.stj.jus.br/portal/site/STJ>. Acesso em: 02 fev. 2015.

Revista do Direitoda UNISC, Santa Cruz do Sul, v.1, n. 45, p. 46- 60, jan. - abri. 2015. 
BULOS, UadiLammêgo. Curso de Direito Constitucional. 8 Ed. São Paulo: Saraiva, 2014.

COMPARATO, Fabio Konder. Função Social da Propriedade dos Bens de Produção. Revista de Direito Mercantil, Industrial, Econômico e Financeiro, página 75, ano XXV (Nova Série), no 63, julho/setembro-1986.

CONTROLADORIA GERAL DA UNIÃO (CGU), INSITUTO ETHOS. A Responsabilidade Social das Empresas no Combate à Corrupção. 2009. Disponível em: <http://www.cgu.gov.br/Publicacoes/etica-eintegridade/arquivos/manualrespsocialempresas_baixa.pdf>. Acesso em: 02.fev. 2015.

DI PIETRO, Maria Sylvia Zanella. Direito Administrativo. 14를 ed. São Paulo: Editora Atlas, 2002.

ETHOS. Glossário de Indicadores. 2013. Disponível em: <http://www3.ethos.org.br/wp-content/uploads/2013/09/Gloss\%C3\%A1rioIndicadores-Ethos-V2013-09-022.pdf>. Acesso em: 02. fev. 2015.

GRAU, Eros Roberto. Elementos de Direito Econômico. São Paulo: Revista dos Tribunais, 1981.

MORAES, José Diniz de. A Função Social da Propriedade e a Constituição Federal de 1988. São Paulo: Editora Malheiros, 1999.

POLACCHINI, Tania Maria Gomes. Responsabilidade Social Empresarial Interna. 2008. Dissertação (Mestrado). Faculdade de Direito Milton Campos. Programa de Pós Graduação em Direito, Nova Lima.

POLETTI, Ronaldo. Coleção Constituições Brasileiras: 1934. - Brasília: Senado Federal e Ministério da Ciência e da Tecnologia, Centro de Estudos Estratégicos, 1999. p. 47.

SILVA, José Afonso da. Curso de Direito Constitucional Positivo. 16. ed. São Paulo: Malheiros, 1999.

TEIZEN JÚNIOR, Augusto Geraldo. A empresa e sua função social. In: Âmbito Jurídico, Rio Grande, XII, n. 65, jun. 2009. Disponível em: < http://www.ambito-juridico.com.br/site/index.php?n_link=revista_artigos_leitura\& artigo_id=6142>. Acesso em: 02 fev. 2015.

TEPEDINO, Gustavo.A Garantia da Propriedade no Direito Brasileiro. Revista da Faculdade de Direito de Campos. a. VI, n. 06, jun. 2005.

THEODORO JÚNIOR, Humberto. O contrato e sua função social. Rio de Janeiro: Forense, 2008.

TOMASEVICIUS FILHO, Eduardo. A função social do contrato:Conceito e critérios de aplicação. Revista de Informação Legislativa, Brasília a. 42 n. 168, p. 197, out./dez. 2005.

Revista do Direitoda UNISC, Santa Cruz do Sul, v.1, n. 45, p. 46- 60, jan. - abri. 2015. 
VEIGA, J.E. Desenvolvimento Sustentável: o desafio do século XXI. Rio deJaneiro: Garamond, 2005.

Revista do Direitoda UNISC, Santa Cruz do Sul, v.1, n. 45 , p. 46- 60 , jan. - abri. 2015. 